\title{
DESENVOLVIMENTO DE UM REPOSITÓRIO PARA OBJETOS DE APRENDIZAGEM DESENVOLVIDOS PELO GICE
}

\author{
Jéssica Magally de Jesus Santos ${ }^{1}$; Gabriela Ribeiro Peixoto Rezende Pinto ${ }^{2}$. \\ 1. Bolsista PIBIC/FAPESB, Graduanda em Engenharia de Computação, Universidade Estadual de Feira de Santana, e-mail: \\ jmagally.ecomp@gmail.com. \\ 2. Orientadora, Departamento de Exatas, Universidade Estadual de Feira de Santana, e-mail: gabrielarprp@ gmail.com. \\ PALAVRAS-CHAVE: Objetos de aprendizagem, Aplicação Web, Processo de \\ desenvolvimento de software
}

\section{INTRODUÇÃO}

Em 2013, a UEFS se tornou polo de aplicação do Programa Nacional de Mestrado Profissional em Ensino de Física (MNPEF). A área de concentração de uma das linhas de pesquisa é a formação de professores de Física em nível de mestrado, abrangendo o "desenvolvimento de produtos e processos de ensino e aprendizagem que utilizem tecnologias de informação e comunicação tais como aplicativos para computadores, mídia para tablets, plataforma para simulações e modelagem computacionais, aquisição automática de dados, celulares e redes sociais" (Linhas de Pesquisa MNPEF-SBF, 2014).

Os mestrandos do MNPEF, juntamente com estudantes do Curso de Engenharia de Computação vinculados ao Grupo de Informática, Conhecimento e Educação (GICE), vêm desenvolvendo Objetos de Aprendizagem (OA) para motivar o processo de ensinoaprendizagem de Física Moderna e Contemporânea (FMC) para o Ensino Médio e Fundamental. Consequentemente, surgiu a necessidade da Implementação de uma Aplicação Web com função de repositório de OA voltados para a aprendizagem de FMC (SANTOS, 2015). O termo OA, segundo Tarouco et al. (2015), geralmente aplica-se a materiais educacionais projetados e construídos em pequenos conjuntos com vistas a maximizar as situações de aprendizagem onde o recurso pode ser utilizado.

A bolsista, vinculada ao projeto de pesquisa "Estudo sobre a adoção do método de aprendizagem baseada em problemas em cursos de graduação e pós-graduação de computação", e ao GICE, identificou a necessidade de expandir esse repositório para atender aos diversos OAs desenvolvidos pelos membros do GICE, visto que os OAs desenvolvidos pelo grupo atendem diversas áreas do conhecimento. Disponibilizar esses recursos didáticos através da internet possibilitará atender à demanda de professores e alunos, tanto aqueles que atuam no ensino médio e fundamental, quanto aqueles que atuam no ensino universitário.

Nesta etapa do processo de desenvolvimento do Repositório de Objetos de Aprendizagem do GICE (ROAGICE), pretendia-se implementar um módulo de administração do sistema, tanto para o referido repositório como para o site do grupo GICE (também desenvolvido pela mesma autora) onde o repositório está incorporado, desenvolvendo assim a parte dinâmica do repositório, o back-end, visto que o mesmo contava apenas com o frontend. Pretendia-se também fazer a hospedagem do site, inicialmente, em um servidor de teste, disponível na internet, e, em seguida, disponibilizá-lo para a comunidade.

O presente trabalho descreve as atividades de Iniciação Científica, que tem como objetivo o desenvolvimento da aplicação web supracitada. Cabe salientar que parte dos resultados apresentados neste resumo também compõe o artigo, escrito pela bolsista, que foi submetido (e aprovado) ao Congresso Brasileiro de Educação em Engenharia (COBENGE), na edição de setembro de 2016 (SANTOS, 2016).

\section{MATERIAIS E MÉTODOS}

$\mathrm{Na}$ primeira etapa do trabalho teve início a revisão bibliográfica acerca de conceitos e tecnologias envolvidas no desenvolvimento de repositórios para Objetos de Aprendizagem. 
Após adquirir tais conhecimentos, o desenvolvimento do projeto foi definido baseando-se no modelo Cascata, seguindo as seguintes etapas:

- Levantamento e Análise de Requisitos: Nesta etapa, foram identificados e definidos novos requisitos para a aplicação.

- Projeto: Nesta etapa, foi realizada a modelagem do sistema, definindo-se as estruturas de dados e tecnologias utilizadas. Foi desenvolvido também, o diagrama entidade relacionamento da base de dados da aplicação.

- Codificação: Nesta etapa do projeto, teve início o desenvolvimento do back-end da aplicação, utilizando linguagem PHP e o banco de dados MySQL. Sendo definidas a funções para manipulação dos dados do sistema no banco de dados. Nesta etapa do projeto também foi realizada a integração back-end e do front-end, assim como o desenvolvimento do front-end específico para o painel de administração do sistema.

- Testes do Sistema: Os testes realizados até o momento correspondem ao comportamento da aplicação em servidor. Os testes foram realizados utilizando o Wampeserver e o serviço de cloud Openshift. Todas as tecnologias e softwares empregados ao longo do projeto possuem suas versões gratuitas disponíveis em seus respectivos sites oficiais.

\section{RESULTADOS E DISCUSSÕES}

Nesta seção serão apresentados os resultados relacionados a etapa de desenvolvimento do ROAGICE. Para poder realizar manipulação dos dados na base de dados da aplicação web foram implementadas funções $C R U D$. Sendo que o $C R U D$ é o acrônimo no idioma Inglês, Create, Read, Update e Delete que em tradução livre para o português significa Criar, Ler, Atualizar e Excluir. Este acrônimo é comumente utilizado para definir as quatro operações básicas usadas em Banco de Dados Relacionais (ARAÚJO, 2015). Tendo início também o desenvolvimento do painel de administração do sistema. Para isso, foi necessário desenvolver as telas que representam a visão do administrador, então, foram implementadas telas como: login, formulários de cadastro para que pesquisadores, OA e artigos possam ser armazenados na aplicação. A Figura 1 apresenta a tela de login.

Figura 1- Tela de login do Administrador do ROAGICE

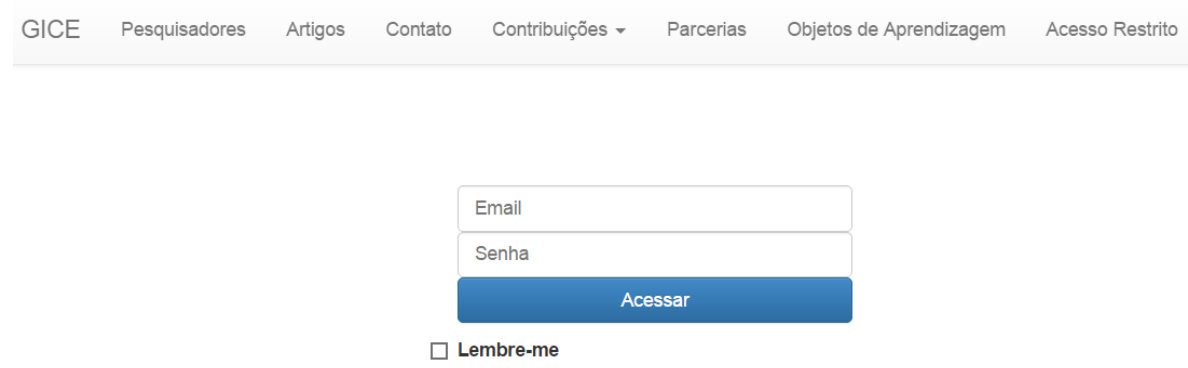

A Figura 1 apresenta a tela de login que permite ao administrador da aplicação web acessar o painel de administração. Para acessar o painel, o usuário deverá clicar em Acesso Restrito no menu na tela inicial do site, assim, a tela de login será carregada. Logo depois, o mesmo deve inserir seus dados de login (email e senha). Os dados inseridos no formulário de login pelo usuário são comparados com os dados do administrador previamente cadastrados no banco de dados da aplicação. Caso algum dado esteja incorreto, o mesmo não terá acesso ao painel de administração e retornará à página inicial do sistema. Caso contrário, o administrador poderá acessar o painel e fazer atualizações nos dados do sistema. A Figura 2 apresenta a visão que o administrador tem dos OA cadastrados na base de dados do ROAGICE.

Figura 2 - Lista de Objetos de Aprendizagem cadastro na base de dados 


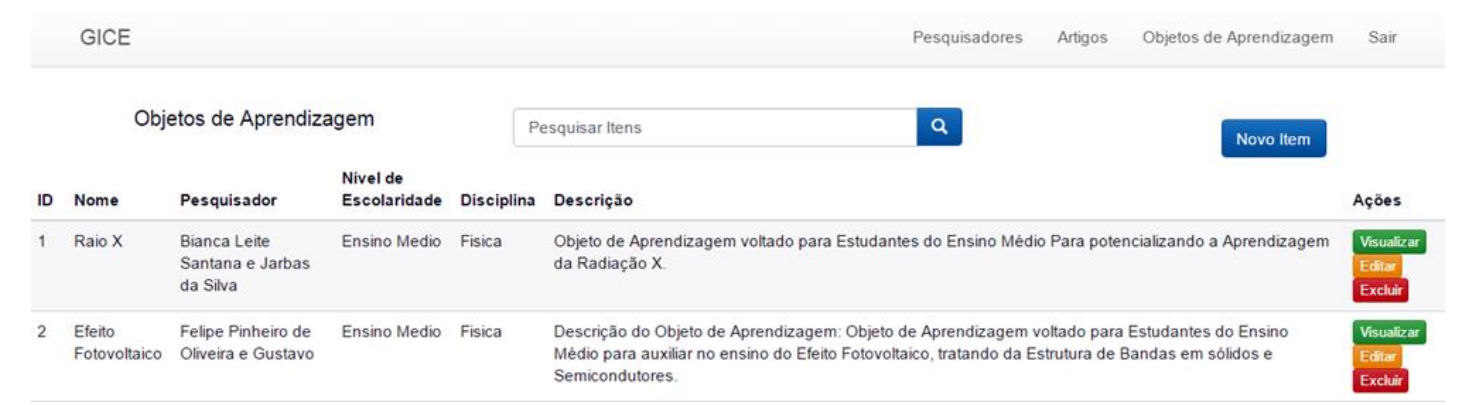

Na Figura 2 pode-se observar a visão do administrador do sistema após clicar no menu na opção Objetos de Aprendizagens. A Figura apresenta uma lista contendo os Objetos de Aprendizagem cadastro na base de dados. Para cada OA cadastrado é apresentado o ID, nome do OA, o pesquisador que desenvolveu o OA, o nível de escolaridade, a disciplina e a descrição do mesmo; e as ações que podem ser feitas pelo administrador, tais como: visualizar todos os dados de OA específico, editar alguma informação ou até mesmo excluir um OA do banco de dados. Para poder visualizar uma lista de pesquisadores e/ou artigos cadastrado no banco de dados do site, o administrador do sistema deve escolher no menu a opção desejada, onde será carregada uma tela com as mesmas opções de ações para pesquisador e/ou artigos. Caso o administrador do sistema deseje cadastrar um novo OA no repositório, deverá clicar no botão Novo Item, onde será carregada uma página com formulário de cadastro, conforme apresentado na Figura 3.

Figura 3- Formulário de cadastro de Objetos de Aprendizagem

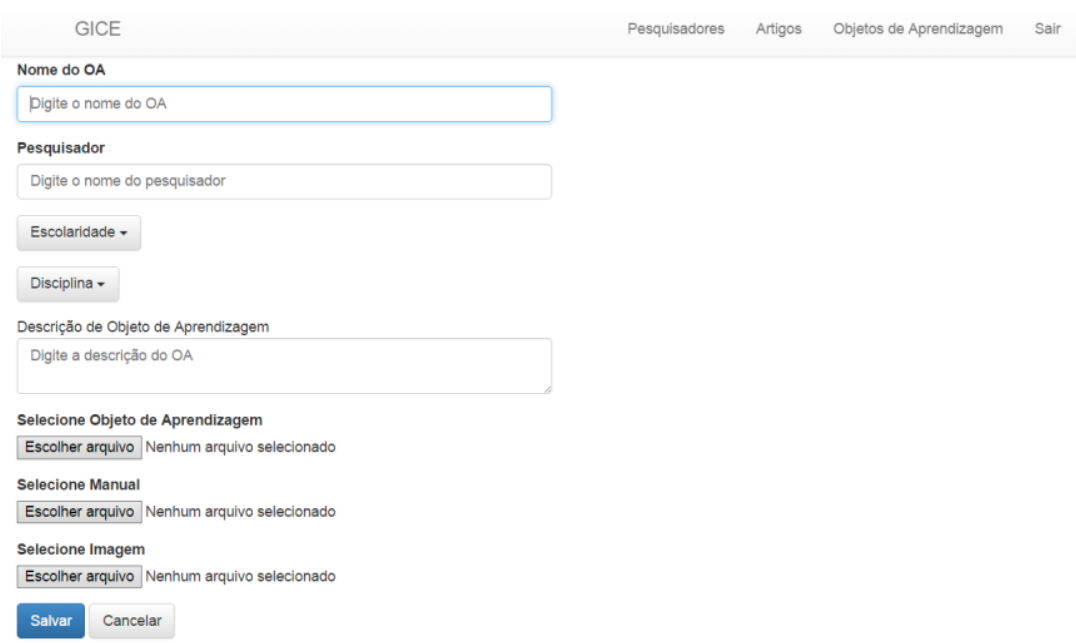

A Figura 3 apresenta o formulário de cadastro de OA. Neste formulário, o administrador da aplicação deve inserir os dados do OA que deseja armazenar no ROAGICE, e clicar no botão Salvar. Quando este botão é clicado, os dados inseridos no formulário serão encaminhados ao arquivo $p h p$ que realizará a operação de inserção no banco. Após o Objeto de Aprendizagem ser inserido no banco, é apresentada ao administrado do sistema a tela com a listagem dos OAs cadastros no sistema conforme a Figura 3. As telas referentes a edição e exclusão de itens do banco de dados ainda estão em desenvolvimento.

Para garantir a segurança do ROAGICE, não é permitido que outro usuário além do administrador tenha acesso ao painel de administração do site através do endereço (URL) das páginas. Para isso foram implementadas medidas de segurança no código fonte do repositório.

Para testar a aplicação, a base de dados foi povoada com os OA voltados para o ensinoaprendizagem de Física do Ensino Médio desenvolvidos por Santana (2015) e Oliveira (2015), conforme apresentado na Figura 2. Os testes realizados até o momento correspondem ao comportamento da aplicação em servidor. Os testes realizados no site foram feitos localmente e remotamente. O teste local foi realizado utilizando o WampServer, verificando se o sistema respondia corretamente às solicitações do usuário, como, por exemplo, fazer 
download de um OA cadastrado no repositório, visualizar ou fazer download do manual contendo a instruções do OA etc.

Os mesmos testes foram feitos remotamente utilizando o serviço de cloud do Openshift, o projeto foi hospedado gratuitamente no Openshift e acessado através da url fornecida pelo mesmo: <http://gice-uefs.rhcloud.com/>. A url foi acessada através de um computador e também de um celular smartphone, sendo compatível com os principais navegadores, atendendo o requisito de suportabilidade do sistema.

\section{CONSIDERAÇÕES FINAIS}

O presente trabalho descreveu as decisões necessárias para o desenvolvimento do ROAGICE, bem como para o desenvolvimento do site para o grupo GICE. A implementação de tais aplicações web contribuiu para agregar mais conhecimentos sobre conceitos e utilizações de linguagens de programação para desenvolvimento web e como elas se relacionam numa arquitetura cliente-servidor. Além de expandir o conhecimento técnico, as atividades desenvolvidas no projeto foram importantes para desenvolver a capacidade sobre gerência de projetos.

Ressalta-se a importância que o desenvolvimento do repositório terá para a comunidade, principalmente para a comunidade de Física, pois o mesmo vai garantir acessibilidade aos Objetos de Aprendizagem, desde que exista conexão com a internet. Os Professores de Física, que cursam Mestrado Nacional Profissional em Ensino de Física, poderão fazer uso dos OAs em suas pesquisas de campos, assim como em suas aulas nas escolas. Já para o grupo GICE, a importância do projeto se dá principalmente pelo fato de poder disponibilizar os OAs desenvolvidos a toda comunidade, auxiliando no processo de ensino-aprendizagem das diversas áreas do conhecimento.

As próximas atividades a serem desenvolvidas dizem respeito à continuação da implementação dos requisitos da aplicação. Também será realizada a disponibilização do repositório de Objetos de Aprendizagem através de um servidor, para que a comunidade tenha acesso.

\section{REFERÊNCIA BIBLIOGRÁFICA}

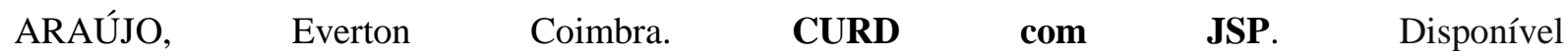
em:<http://www.linhadecodigo.com.br/artigo/2997/crud-com-jsp.aspx\#ixzz3xbHxP2na> Acesso em 19 de nov. de 2015.

Linhas de Pesquisa MNPEF-SBF. Disponível em:< http://dfis.uefs.br/pg/mnpef/viewpage.php?page_id=3 > Acesso em 12 de jun. de 2014.

OLIVEIRA, Felipe Pinheiro de. Desenvolvimento de um Objeto de Aprendizagem Voltado para Estudantes do Ensino Médio para Potencializar a Aprendizagem do Efeito Fotovoltaico: Estrutura de Bandas nos Sólidos e Semicondutores. Trabalho de Conclusão de Curso em Andamento. Universidade Estadual de Feira de Santana. Feira de Santana, 2015.

SANTANA, Bianca Leite. Desenvolvimento de um Objeto de Aprendizagem voltado para Estudantes do Ensino Médio para Potencializar a Aprendizagem da Radiação X. Trabalho de Conclusão de Curso em Andamento. Universidade Estadual de Feira de Santana. Feira de Santana, 2015.

SANTOS, Jéssica Magally de Jesus. Implementação de uma Aplicação Web com função de repositório de Objetos de Aprendizagem voltados para a aprendizagem de Física Moderna e Contemporânea de estudantes do Ensino Médio e Fundamental. XIX Seminário de Iniciação Científica da UEFS. Universidade Estadual de Feira de Santana. Feira de Santana. 2015.

SANTOS, Jéssica Magally de Jesus; PINTO, Gabriela R. P. R. ROAGICE: Implementação de um Repositório de Objetos de Aprendizagem. XLIV Congresso Brasileiro de Educação em Engenharia. TAROUCO, Liane M. R.; FABRE, Marie-Christine J. M.; TAMUSIUNAS, Fabrício R. Reusabilidade de objetos educacionais. em:<http://www.nuted.ufrgs.br/oficinas/criacao/marie_reusabilidade.pdf> Acesso em Acesso em 19 de nov. de 2015. 